\title{
TRENDOVI U OTVORENOM UČENJU NA DALJINU U SVETU I KOD NAS
}

\author{
Ivona Zenović ${ }^{1}$, Ivan Bagarić ${ }^{2}$ \\ ${ }^{1}$ Internacionalni Univerzitet u Novom Pazaru \\ ${ }^{2}$ Univerzitet Singidunum, Beograd
}

\begin{abstract}
:
Još 1998. godine, moćna Nacionalna fondacija za nauku SAD (National Science Foundation) organizovala je važno savetovanje na Univerzitetu u Majamiju gde su učesnici, između ostalog, definisali faktore koji će biti pokretači promena u 21. veku. Pored tehnologije i promena u poslovnom okruženju na prva dva mesta, na sedmom i poslednjem mestu našlo se obrazovanje i obuka. Postojeća struktura obrazovnog sistema, zaključeno je tada, posebno na univerzitetskom nivou, ocenjuje se kao kruta i nesposobna da se menja u skladu sa zahtevima promenljivog svetskog okruženja. Kao jedna od šest očekivanih promena obrazovnog sistema navedena je promena načina isporuke obrazovanja, u smislu iskorišćavanja prednosti koje donose komunikacione i multimedijalne tehnologije uključujući Internet, za oblikovanje novih načina nastave i novih načina dostavljanja nastavnog materijala studentima.

Ovu tadašnju prognozu danas prepoznajemo kao sistem učenja na daljinu (UND), široko razvijen način transfera znanja u velikom delu sveta sveta, ponajviše baš u SAD. Namera autora je da izloži razvoj UND, prikaže vrste i oblike učenja na daljinu, kao i načine prenosa informacija u sistemu UND. Data su neka od vodećih rešenja u Evropi i svetu i navedeni problemi na koje se nailazi prilikom uvođenja sistema UND, kao i problemi u praksi.
\end{abstract}

\author{
Key words: \\ Internet, \\ Visoko obrazovanje, \\ Učenje na daljinu, \\ Elektronsko učenje, \\ Trendovi.
}

\section{UVOD}

Još 1998. godine, moćna Nacionalna fondacija za nauku SAD (National Science Foundation) organizovala je važno savetovanje na Univerzitetu u Majamiju gde su učesnici, između ostalog, definisali faktore koji će biti pokretači promena u 21. veku. Pored tehnologije i promena u poslovnom okruženju na prva dva mesta, na sedmom i poslednjem mestu našlo se obrazovanje i obuka. Kao jedna od šest očekivanih promena obrazovnog sistema navedena je promena načina isporuke obrazovanja, u smislu iskorišćavanja prednosti koje donose komunikacione i multimedijalne tehnologije uključujući Internet, za oblikovanje novih načina nastave i novih načina dostavljanja nastavnog materijala studentima.

Uz pomoć Interneta, čiji je razvoj dobio krila baš u drugoj polovini 90-tih godina, ova promena je realizovana u smislu snažnog razvoja učenja na daljinu odmah s početka 21. veka. Učenje na daljinu jedna je od alternativnih metoda interaktivnog učenja putem najveće globalne računarske mreže, primenom novih metoda i alata učenja. U ovom obliku edukacije, predavači i studenti fizički su odvojeni, ali snažno povezani novim tehnologijama.

\section{ISTORIJSKI RAZVOJ UČENJA NA DALJINU}

Učenje na daljinu je vid obrazovanja koji je nastao još u prvoj polovini 19. veka. Veruje se da je prvi pionir bio Englez, Isak Pitman. Kako bi se prevazišle različite prepreke kao vreme, prostor ili skromna finansijska sredstva $i$ tako izašlo u susret marginalizovanim grupama, pre svega ženama, koje u tadašnjem obrazovnom sistemu nisu imale adekvatan pristup obrazovnim sadržajima. Ukoliko želimo preciznije utvrditi početak ovog vida obrazovanja, prihvatimo 1858. godinu, kada je Londonski univerzitet svojom odlukom da dozvoli polaganje ispita bez prethodnog posećivanja predavanja utemeljio prvi zvanični oblik učenja na daljinu u vidu dopisnih kurseva. 
U to vreme, primenjena tehnologija je bila daleko jednostavnija u odnosu na današnju, pisma su prenošena kočijama, i u njima su bili sadržaji za učenje, praktično, ono što bismo danas nazvali nastavnim materijalima. Pojedinci su mogli da se prijave da dobijaju ta pisma. Generacije misionara i prosvetitelja su na ovaj način širili informacije i znanja.

Učenje na daljinu je uvek bilo alternativa klasišnom obrazovanju, često osporavana i odbacivana. Taj stav se vremenom menja, pre svega u zemljama Zapadne Evrope i Severne Amerike, kako se u koncept obrazovanja na daljinu ugrađuju sve savremenije informaciono-komunikacione tehnologije (IKT). Negde od početka devedesetih godina prošlog veka, taj spoj obrazovanja na daljinu uz upotrebu IKT-a dobija naziv i formu onoga što danas zovemo on-line obrazovanjem na daljinu.

Pojavom radijskog, a kasnije televizijskog programa, otvorila se nova era učenja na daljinu. Od 1920. godine, radijski program je počeo da se koristi kao medij za učenje na daljinu, a njegovu ulogu je potom dopinila, pa čak i preuzela televizija, tridesetak godina kasnije. Tako je, na primer, na američkom univerzitetu Wisconsin u gradu Madison, nakon što je 1922. godine počeo da se emituje radijski program, već 1952 , godine startovao i televizijski obrazovni program WHA-TVI. U istom periodu, u nekim slučajevima se koristila i postojeća PTT infrastruktura, da bi se kao posebna metoda učenja na daljinu održavale audio konferencije koje su omogućavale, ne samo komunikaciju predavač-učenik, već i razmenu ideja među samim učenicima.

Od 1980. godine, počela je implementacija računarskih mreža, što je omogućilo da se komunikacija između učesnika programa učenja na daljinu podigne na viši nivo. Ovo je naročito došlo do izražaja u slučajevima kada se računarska komunikacija odvijala putem optičkih veza. Najveći pomak u učenju na daljinu je svakako donela pojava Interneta i tehnologija vezanih za njega. Internet je omogućio da se primenom savremenih komunikacionih tehnologija, učenik u okviru programa učenja na daljinu ne oseća toliko "udaljen" koliko je to bio slučaj pre njegove pojave. Komunikacija koja se ranije odvijala uglavnom u smeru predavač-učenik, sada je postala raznovrsnija, i to čak u onom najkvalitetnijem audiovizuelnom obliku. Tako su danas uz pomoć Interneta omogućene veze: učenik-obrazovni materijal, predavač-učenik, učenik-učenik, učenik-predavač, učenik-obrazovni materijal na drugim lokacijama, učenik-drugi predavači, itd.

Dobar primer za praćenje razvojnog puta učenja na daljinu je britanski Otvoreni univerzitet, institucija koja već decenijama pruža usluge obrazovanja na daljinu, a koja je osnovana 1969. godine. Ovaj univerzitet je u Velikoj Britaniji ranije bio osporavan, zbog velikih troškova koje je država izdvajala za njega, da bi danas imao veliki ugled, ne samo u Velikoj Britaniji, već i u svetu.

\section{TRENDOVI RAZVOJA UČENJA NA DALJINU}

Razvoj učenja na daljinu dostigao je danas zavidan nivo koji se karakteriše izborom ovog savremenog načina obrazovanja u velikom broju svetski značajnih visokoškolskih institucija kroz veoma ozbiljne i cenjene programe. Ne manje važna je njegova primena u ostalim obrazovnim institucijama nižeg nivoa veoma zastupljenim u nekim delovima sveta. Ukupan broj polaznika dostiže stotine miliona a prognoze govore da će polovina svih kategorija obrazovanja biti sprovedena kroz učenje na daljinu do kraja tekuće dekade.

To se najbolje nazire iz razvoja obrazovanja na daljinu $\mathrm{u}$ devet zemalja sa veoma visokom populacijom (Bangladešu, Brazilu, Kini, Egiptu, Indiji, Indoneziji, Meksiku, Nigeriji i Pakistanu, koje se nazivaju E-9 zemlje) gde je preporučeno da se usredsrede na „proširenje rada za jednakost škola, za obrazovanje nastavnika, i za neformalno obrazovanje, posebno u vezi sa zdravljem." Razvijene su strategije za ove oblasti koje bi mogle korisno da se primenjuju u većini, ako ne i u svim E-9 zemljama. Strategije niske tehnologije i emitovanja daju snažne cifre, ali postoji takođe i sve veći broj projekata koji inovativno koriste nove informacione tehnologije.

U Evropi je otvoreno učenje i učenje na daljinu već afirmisan oblik obrazovanja, iako status i tradicija znatno variraju unutar regiona. U Zapadnoj Evropi postoji snažan privatni sektor okrenut odrasloj populaciji, sa sadržajima programa opšteg obrazovanja na nivou srednje škole, raznim oblicima stručnog obrazovanja i obuke, i neformalnog obrazovanja. Sa druge strane, Francuska, Španija i Švedska su osnovale institucije koje finansira vlada i koje uglavnom nude obrazovanje na nivou srednje škole, dok neke druge zemlje organizuju i visokoškolske programe.

Na najvišem nivou je Otvoreni univerzitet Velike Britanije koji je postavio je standarde za ovu kategoriju obrazovanja i ovu vrstu institucije. Pored njega, slične vodeće institucije su osnovane u Španiji sa Universidad Nacional de Educación a Distancia (UNED) i Universitat Oberta de Catalunya (UoC), Nemačkoj sa Fernuniversität, kao i Otvoreni univerzitet u Holandiji i Universidade Aberta u Portugaliji.

U Centralnoj i Istočnoj Evropi, kao i zemljama bivšeg SSSR-a, političke i ekonomske transformacije su imale značajan uticaj na obrazovanje, i već su dovele do suštinskih reformi i restrukturiranja nacionalnih obrazovnih sistema. U većini zemalja, razvijeno je obrazovanje na daljinu na osnovu studija prepiski u kombinaciji sa „,konsultacijama“ licem u lice, i služe velikim populacijama. Otvoreno učenje i učenje na daljinu je i dalje prioritet većini vlada u ovom podregionu, ali mu je potrebna temeljna reforma i nadogradnja, kao što je potrebna i obrazovnom sistemu u celini. Razvoj novih struktura će zahtevati podršku u obliku finansiranja i regionalne saradnje da bi bio efikasan, kao što su PHARE i TACIT programi Evropske komisije.

Afrika je jedna od regija gde se otvoreno učenje i učenje na daljinu uglavnom koristi za proširenje pristupa osnovnom obrazovanju i za održavanje i poboljšanje kvaliteta konvencionalnog obrazovnog sistema, posebno putem stručnog usavršavanja nastavnika. Na primer, UNESCO je bio uključen u stručno obrazovanje svih nekvalifikovanih nastavnika u Bocvani u kasnim 1960-im i 1970-im. Otvoreno učenje i učenje na daljinu se takođe 
koristilo u neformalnom obrazovanju i razvoju zajednice od strane nacionalnih i međunarodnih organizacija. Jedan od ranih primera je pan-afrička INADES formacija (afrički Institut za ekonomski i društveni razvoj), koji je osnovan 1962. u Obali Slonovače, s nacionalnim kancelarijama u 10 zemalja.

U Severnoj Americi, istorija obrazovanja na daljinu doseže više od stotinu godina unazad, a sada je čvrsto ukorenjena u obrazovne sisteme SAD i Kanade. Postoji veliki broj programa i institucija u raznim oblastima, a tu su i primeri upotrebe svih dostupnih tehnologija. Obrazovanje na daljinu se koristi za komunikaciju sa udaljenim grupama stanovništva, podršku školskom obrazovanju, i mogućnosti obuke odraslih, stručne kurseve, poslovnu i vojnu obuku, više i kontinuirano obrazovanje, kurseve životnog obogaćivanja, itd. Modaliteti koji su u čestoj upotrebi su Web-nastava, komunikacija posredstvom kompjutera, video telekonferencije, satelitski prenos, televizijski i video kursevi, i obrazovanje prepiskom često dopunjavano upotrebom CD-ROM-ova i video kaseta.

U obe zemlje obrazovanje je u nadležnosti pojedinih država/pokrajina. Postoji varijacija u pogledu koje države/ pokrajine obezbeđuju sredstva i infrastrukture za podršku pristupu mogućnostima nastave i sredstava na daljinu. U određenom broju država i pokrajina postoje snažne inicijative za pomoć školama kod nabavke sisteme video konferencija i obezbeđenja pristupa Internetu u učionicama. Ovi napori su u SAD dobili podršku putem nacionalnog programa E-Rate koji obezbeđuje značajne popuste za škole kod pristupa telekomunikacijama i tehnologijama. Tokom prve godine programa, na primer, Internet pristup je obezbeđen za oko 500.000 učionica.

Druga nacionalna inicijativa SAD-a je usmerena na obuku nastavnika kako da uspešno koriste nove tehnologije. Program Priprema nastavnika sutrašnjice je pomogao stotinama visokoškolskih institucija širom SAD da obuče nastavnike za korišćenje modernih tehnologija za učenje. Značaj zadovoljavanja potreba zapostavljenih domorodačkih naroda je priznata u SAD-u, i nacionalna inicijativa sada se usmerava na obezbeđenje pristupa Internetu u učionicama svih indijanskih škola pod federalnom podrškom.

I u Kanadi i u SAD-u, došlo je do eksplozivnog rasta broja osnovnih i poslediplomskih studija koje se nude preko World Wide Weba. Pored ponude već poznatih univerziteta, pojavio se određeni broj profitnih online univerzitetskih kompanija kao što su Univerzitet Capella i Međunarodni univerzitet Jones, koji su akreditovani i sada nude isključivo Web studijske programe.

Među istaknutim davaocima usluga obrazovanja na daljinu u SAD-u su nekoliko uobičajenih univerziteta, privatnih institucija nastave na daljinu, institucija vojne obuke, RTV servisa, nekoliko privatnih korporacija, i u poslednje vreme, niz različitih konzorcijuma. Jedan od njih je Nacionalni tehnološki univerzitet (NTU). U Kanadi, postoji nekoliko jakih pokrajinskih institucija na nivou srednje škole kao i na nivou univerziteta, a takođe i obrazovni televizijski servisi. Na primer, postoje specijalizovani univerziteti nastave na daljinu u Kvebeku, Alberti i Britanskoj Kolumbiji. Modeli konzorcijuma su takođe razvijeni u mnogim pokrajinama.

\section{PROBLEMI PRILIKOM UVOĐENJA UČENJA NA DALJINU}

Najveći problem kod učenja na daljinu je nedostatak upornosti i sposobnosti polaznika da uspešno savladavaju sve faze kursa, od upisa na on-line kurs ili program, prilagođavanja formi rada, aktivnog učestvovanja u njegovom izvođenju i uspešnog završetka. Mnogi programi učenja na daljinu ne uspevaju, jer veliki broj polaznika odustaje i nikada ne završi program do kraja. U ranoj fazi ovog vida obrazovanja, stepen odustajanja polaznika bio je čak veći od $60 \%$.

Postoje više razloga ovakvog odustajanja. Jedan od najvećih problema je sama priroda ove vrste učenja. $\mathrm{Za}$ razliku od tradicionalnog učenja, ovde je vrlo lako odustati, jer se od polaznika ne očekuje da se fizički pridruže razredu, grupi ili godini, tj. da dolaze u obrazovnu ustanovu, gde ih susreću kolege i nastavnici, nego kurs pohađaju izolovani, najčešće od kuće ili sa posla. Kako su polaznici uglavnom zaposleni i preopterećeni drugim obavezama, potrebna im je velika samodisciplina i motivacija, sa jedne strane, i značajno podsticajno angažovanje nastavnika i mentora, sa druge strane, koji će pratiti njihovo napredovanje, neprestano im pružati podršku i pomoć pri učenju i podsticati ih da izvršavaju svoje zadatke.

Direktna posledica koncepta učenja na daljinu je izostanak ličnog kontakta među polaznicima, što kod jednog dela njih stvara dodatni problem. Kontakt uživo, kako sa nastavnicima, tako i sa ostalim polaznicima nije ovde prisutan, i nekim polaznicima koji su navikli na „stalnu pomoć sa strane", takav oblik rada van grupe nije prihvatljiv. Zbog takve izolovanosti, pojedincima je potreban visok stepen aktivnosti i discipline kako bi se oni prilagodili ovim uslovima i ostali na kursu.

Nedostaci kod učenja na daljinu vezani su i za tehnologiju koja se koristi za izvođenje kurseva. Svi polaznici moraju imati na raspolaganju odgovarajuću tehnologiju, na primer, računar sa novijom verzijom nekog Web pretraživača, programe za prikaz multimedijskih zapisa, priključak na Internet, adekvatnu brzinu prenosa informacija, prostoriju za nesmetani rad, itd. Tehnologija koja se koristi za neki kurs može biti i zahtevna (na primer, kod videokonferencija), pa tako i onemogućiti da kurs pohađaju oni polaznici kojima ona nije dostupna.

Problem za neke polaznike, pa i mentore ili tutore, može predstavljati i samo korišćenje tehnologije ukoliko se teško familijarizuju sa njom. Često moraju uložiti dodatno vreme da bi se, pored sadržaja kursa, savladala tehnologija koju je potrebno koristiti. Ponekad, tehnologija nije pouzdana, te može doći do različitih zastoja i kvarova, što deluje frustrirajuće na polaznike, ponekad organizator kursa menja softverske pakete u želji da unapredi transfer materijala, što zahteva nove napore polaznika, a ponekad postojeći softverski alati nisu kvalitetni i postaju zamorni polaznicima. Sve to dodatno utiče na odustajanje polaznika od kursa. 


\section{OBLICI I REŠENJA UČENJA NA DALJINU}

Jedan od velikih problema prilikom definisanja samog e-učenja je razlika u shvatanju ovog kompleksnog oblika učenja i pokušaj klasifikacije brojnih rešenja. Nove Internet tehnologije omogućavaju upotrebu raznih zapisa (tekst, audio i video), koji se kombinuju u multimedijalni sadržaj i prezentuju studentu. Učenje je proces koji podrazumeva lepezu mogućih aktivnosti, od jednostavnog čitanja teksta ka složenijim strukturama kao što je audiovizuelna percepcija sadržaja ili aktivno učestvovanje u nastavi, kooperativno učenje i tako dalje.

U sadašnjem tehnološkom razvoju informacionih tehnologija i trendova distance learning-a uopšte, u zavisnosti od same vrste znanja i veština koje treba da prenese svojim budućim studentima, mentor se opredeljuje za primenu kombinacije nekoliko različitih oblika edukacije. To su: e-mail učenje, elektronske knjige, striming mediji, edukativni programi, on-line kursevi i Web dnevnik. Kombinovanje pojedinih rešenja će se izvoditi isključivo u zavisnosti od zahteva koje određeni kurs u smislu svojih specifičnosti izvođenja postavlja pred nastavnika odnosno studenta.

E-učenje je jedan od najpoznatijih računarski generisanih komunikacionih servisa. Kao koristan alat našao je svoje mesto i u obrazovnim programima.

Elektronske knjige koriste se u sistemu elektronskog učenja kao priručnik ili kompletan kurs. Moguće je kombinovati grafičke, audio i video zapise. Najčešće je u formatu sa ekstenzijom .pdf (Adobe Acrobat), ali može da bude .exe ili neki drugi prepoznatljiv format kao što je html.

Striming mediji predstavljaju jedno od rešenja koje e-učenje čini jedinstvenim i privlačnim. Korišćenje multimedijalnih tehnologija (sinteza audio i vizuelne komunikacije) omogućava prezentaciju obrazovnog sadržaja na dinamičan i eksplicitan način. Praćenje predavanja ili vežbi uživo upotrebom ovih medija omogućava studentu da događaje vezane za e-učenje prati iako je dislociran. U okviru e-učenja organizuju se predavanja u formi veb konferencije (Web-conference), veb prenosa (Webcasts) ili veb seminara (Webinars). Za prisustvo studenta je dovoljno da ima administrativno odobren pristup i da bude u zakazano vreme u virtuelnoj učionici. Ove tehnologije omogućavaju učestvovanje u diskusijama, interaktivan rad u realnom vremenu, itd.

Edukativni programi se dugo koriste u obrazovanju. Primenjeni u e-učenju dobijaju nov i dinamičan oblik. Ti novi programi (pametne igre) interesantni su polaznicima, posebno mlađeg uzrasta. Autori edukativnih programa i simulacija trude se da poučavanje i način prezentacije budu stimulativni. U formi 3D interaktivnih simulacija, zabavnih igrica ili kvizova, plasiraju se vrlo ozbiljni nastavni sadržaji.

On-line kursevi (Courseware) verovatno su najpoznatiji oblik e-učenja. Mnoge obrazovne institucije imaju u svojim ponudama on-line kurs kao rešenje za studente koji nisu u mogućnosti da prisustvuju nastavi u školskoj ili univerzitetskoj učionici. Sa novim koncepcijama oni vode studenta kroz sadržaj na način koji im omogućuje napredovanje. Kroz različite radionice sprovode se vežbe i stiču neophodna znanja. Na kraju kursa polaže se ispit u obrazovnoj instituciji. Tako je omogućeno da student stekne kredite za položene predmete ili diplomu ako položi sve propisane ispite nekog univerziteta.

Web dnevnik (Web logging, blogging) skraćeno blog, kao i svaki novi koncept, teško je definisati dok se sâm ne iskristališe. To je veb stranica koju sami uređujemo. Možemo blog opisati kao dnevnik pojedinca ili interesne grupe. Blogging stranica koja se koristi u e-učenju predstavlja interaktivnu razmenu znanja, komunikaciju između studenata ili interesnih grupa. Neki autori objašnjavaju weblog kao lično izdavaštvo na vebu i u delu zajednice. Posetioci bloga mogu unositi svoje komentare direktno na veb strani, na određeni link ili poslati e-mail.

\section{PROJEKTOVANJE I IMPLEMENTACIJA MODELA UČENJA NA DALJINU}

Istraživanje je sprovedeno $u$ visokoobrazovnim institucijama u Vojvodini. Eksperiment je obavljen na postojećoj mrežnoj infrastrukturi i postojećim računarima u kabinetima na Visokim tehničkim školama strukovnih studija u Zrenjaninu i Novom Sadu. Pre nego što je počelo istraživanje, dobijena je saglasnost direktora škola, profesora i asistenata koji izvode nastavu u tim školama tj. fakultetu.

U ostvarivanju osnovnih zadataka škola objedinjuje obrazovni, istraživački i stručni rad i druge delatnosne celine kao delove jedinstvenog procesa visokog strukovnog obrazovanja, sa svrhom neprekidnog razvoja i unapređenja nastavne delatnosti, zadovoljenja potreba, zahteva i očekivanja studenata, zaposlenih i društva u celini. Nastava se izvodila na sledećim smerovima:

- VSZR - proizvodno mašinstvo i računarske tehnologije, procesno i poljoprivredno mašinstvo; predmet Tehničko crtanje

- VSNS - proizvodni inženjering, termoenergetika i održavanje, bezbednost i zdravlje na radu; predmet Tehničko crtanje sa nacrtnom geometrijom.

$\mathrm{Za}$ odabrani model eksperimenta sa paralelnim grupama bilo je potrebno pratiti sledeće korake: izraditi eksperimentalni program rada, pripremiti paralelne forme instrumenata za utvrđivanje rezultata inicijalnog i finalnog merenja, ujednačiti eksperimentalnu (E) i kontrolnu gru$\mathrm{pu}(\mathrm{K})$ prema relevantnim varijablama (ličnost ispitanika: pol, osnovna računarska pismenost, predispozicije prema učenju na daljinu, predznanje iz oblasti nacrtne geometrije). Podela studenata na kontrolnu tj. eksperimentalnu grupu na godini urađena je na osnovu slučajnog izbora. U istraživanju je učestvovalo 127 studenata, od toga $65 \mathrm{u}$ kontrolnoj grupi i $62 \mathrm{u}$ eksperimentalnoj grupi.

Realizacija istraživanja je prvo obuhvatala predistraživanje. U predistraživanju su izvršene provere o osnovnoj računarskoj pismenosti studenata, utvrđivanje njihovih predispozicija za učenje na daljinu, sprovedena je anketa o stavovima i mišljenju studenata o učenju na daljinu, anke- 
ta o stavovima i mišljenju profesora o uvođenju učenja na daljinu, izmeren je motiv postignuća studenata i urađen je inicijalni test o njihovom znanju nacrtne geometrije. Posle urađenog predistraživanja, pristupilo se izvođenju eksperimenta.

Inicijalno ispitivanje urađeno je na početku prvog semestra školske 2009/10. god. na VSZR i VSNS. Potom je usledila primena eksperimentalnog programa koji je trajao sedam nedelja. Finalno merenje sledilo je polovinom decembra 2009. god. (VSZR,VSNS), a provera trajnosti znanja izvršena je u januaru 2010. god. (VSZR,VSNS).

U predmetu istraživanja odabrana je eksperimentalna provera primene modela za unapređivanje efikasnosti nastave grafičkih komunikacija, pa se u skladu sa postavljenim ciljem i zadacima istraživanja pristupa eksperimentalnoj proveri postavljenih hipoteza istraživanja. Eksperiment je izveden na sledeći način: profesori/asistenti su sa studentima kontrolne grupe, $u$ nastavi realizovanoj na tradicionalan način, obradili predviđene nastavne jedinice, dok su studenti eksperimentalne grupe obradili tu nastavnu jedinicu korišćenjem sistema za učenje na daljinu.

Nakon završenog eksperimenta urađene su ponovo ankete o stavovima i mišljenju studenata eksperimentalne grupe o učenju na daljinu, da bi se utvrdilo da li su nastupila drugačija mišljenja i stavovi, kao i finalni test, da bi se utvrdilo u kojoj meri i kako je savladano predviđeno gradivo.

Završetkom eksperimenta i prikupljanjem podataka, moglo se pristupiti obradi rezultata.

\section{ZAKLJUČAK}

Čovek komunicira multimedijalno i njegov svet je u suštini multimedijalan, pa nije ni čudna njegova težnja da to prenese u nastavni proces. Svaki sistem učenja na daljinu treba da obezbedi: širok izbor modela učenja, koji odgovara svakoj ličnosti, individualizaciju obima i složenosti nastavnih materijala, načina i tempa njegove obrade, individualizaciju u odnosu na tempo učenja i u odnosu na sposobnosti i osobine ličnosti učenika. Nova tehnološka dostignuća ulivaju nam nadu da će čovek uskoro moći da "zagolica" sva svoja čula putem mašina, a ne samo vida, sluha i dodira.

Korišćenje tehnologije za unapređenje obrazovnog procesa počinje istraživanjem kako ljudi uče, odnosno kako oni uče efikasnije i uspešnije. Utvrđeno je da se korišćenjem informacionih tehnologija povećava iskustvo u učenju i poboljšava efikasnost, a u nekim slučajevima ostvaruje jedini mogući vid obrazovanja. Uporedo sa tim, smanjuju se i troškovi učenja. Tradicionalni koncept obuke u učionici postepeno gubi dominantnu ulogu koju je imao sve donedavno. Nova paradigma učenja svakako će biti elektronsko učenje.

Obrazovanje je do sada bilo fokusirano na tradicionalni sistem školovanja. Sa razvojem elektronskog učenja taj fokus se premešta na intelektualne potrebe individualnog korisnika, učenika, studenta. Digitalno doba će značajno uticati na obrazovanje i radikalno će izmeniti postojeći proces učenja i podučavanja. U mnogim zemljama već su pokrenute, ili se pokreću inicijative, koje će označiti revoluciju u korišćenju novih tehnologija u obrazovnim institucijama.

Nagli tehnološki progres utiče na život ljudske populacije. Obilje novih naučnih informacija zahteva usavršavanje u struci tokom celokupnog radnog veka. Kvalitetan sistem obrazovanja treba da bude dobro osmišljen, da predstavlja visokoškolski sistem zemlje koji je zakonski regulisan. Zadatak visokoškolskog obrazovanja može da se ostvari putem prenošenja i usvajanja naučnih saznanja i vrednosti iz nauke, tehnike, umetnosti i kulture, zatim, putem razvijanja navika i veština tj.razvijanjem sposobnosti ličnosti da se koristi stečenim znanjima, ali da istovremeno stiče nova znanja i vrednosti.

Za sponzorstva i finansiranje treba se zahvaliti ovde. Ovde takođe treba izraziti zahvalnost onima koji su pomogli u radu na izradi rukopisa. Na primer: P. P. želi da se zahvali... Zahvalite se sponzoru na prvoj strani u fusnoti bez broja.

\section{LITERATURA}

[1] Carol Fallon, and Sharon Brown, (2003). e-Learning Standards, CRCpress.

[2] Đurović, I., Ranđić, D., and Bagarić, I.,: „The implementation of new management experiences in higher education teaching - distance learning “, International Conference on Information Technology and Development of Education, Itro 2011, July 2011, Zrenjanin, Republic of Serbia.

[3] Marošan, Z., (2006): Učenje na daljinu u zemljama tranzicije sa posebnim osvrtom na visoko obrazovanje u AP Vojvodini, Doktorska disertacija, Tehnički fakultet "Mihajlo Pupin”, Zrenjanin.

[4] Savić, A., (2006): Metode razvoja i primena XML web servisa kao podrška tradicionalnom obrazovnom procesu, Doktorska disertacija, Tehnički fakultet „Mihajlo Pupin“, Zrenjanin.

[5] Valery, O.K., Volodymir, M.K., Olexanndr P.S. (2002). Distance Learning, Lifelong Learning in Europe 2, (pp 114119).

[6] Zenović, I., (2012): Primene novih menadžment iskustava u nastavi visokog obrazovanja - učenje na daljinu, Doktorska disertacija, Fakultet za preduzetni menadžment Novi Sad, Univerzitet Alfa

[7] Zenović, I., Ranđić, D., and Bagarić, I.,: „The electronic learning standards“, XIII International SymposiumSYMORG 2012, June 5-9 2012, Zlatibor, Serbia, Proceedings, pp. 1861-1865.

[8] Zenović, I., Ranđić, D., i Bagarić, I.,: „Koncept otvorenog učenja i učenja na daljinu“, Festival kvaliteta 2012, 39. Nacionalna konferencija o kvalitetu (sa međunarodnim učešćem), Kragujevac 7-9 juni 2012, Mašinski fakultet Univerziteta u Kragujevcu. 


\section{Abstract:}

Back in 1998 the powerful National Science Foundation organized a conference at the University of Miami, where participants, among other issues, discussed and defined the factors expected to be the drivers of change in the 21 st century. Beside technology and changes in the business environment occupying the first two places on the list of the factors mentioned, education and training were at the seventh and last position in the list. On that occasion it has been concluded that the current educational system structure, particularly at the university level, is viewed as rigid and unable to change to meet the demands of the changing world environment. One of the six changes expected to deserve attention was the change in the mode of education delivery, taking into account the advantages brought about by new comunication and multimedia technologies, including Internet, with a view to researching new teaching methods and new modes of teaching materials delivery to students.

The diagnosis established on that occasion is now recognized as the system of long-distance learning (LDL), nowadays a widely used way of knowledge transfer all over the world, and especially in the USA. The intention of the authors is to give a overview of the development of LDL and to present the types and forms of LDL as well as knowledge-transfer modes devised within the LDL framework. The paper explores some of the leading LDL solutions adopted in Europe and worldwide, but also points out some difficulties that may be encountered while implementing the system of LDL, as well as some problems arising in practice.

\section{Key words:}

Higher education, Long-distant learning, E-learning, Advantages and Disadvantages, Trends of development. 